\title{
AS CONSTRIBUIÇÕES DO PEDAGOGO PARA A PROMOÇÃO DA INTEGRALIDADE DA ATENÇÃO E DO CUIDADO PRESTADOS A ADOLESCENTES EM UNIDADES DE SEMILIBERDADE NO DISTRITO FEDERAL
}

\author{
THE CONTRIBUTIONS OF TEACHER TO PROMOTE THE COMPLETENESS OF \\ ATTENTION AND CARE SERVICES TO TEENS FREE RANGE UNITS IN FEDERAL \\ DISTRICT
}

\author{
Alex Leonardo Ribeiro ${ }^{1}$ \\ Universidade de Brasília \\ Clélia Maria de Sousa Parreira Ferreira² \\ Universidade de Brasília \\ Oviromar Flores 3 \\ Universidade de Brasília
}

\begin{abstract}
Resumo
Este artigo tem como objetivo discutir as contribuições do pedagogo como membro de equipes multiprofissionais, que têm como atribuições a garantia do cuidado e da atenção integral de adolescentes em conflito com a lei. Nesse sentido, busca caracterizar a integralidade em saúde no regime de semiliberdade; especificar o papel do pedagogo em atuação em espaços não escolares; verificar as interrelações entre equipe de trabalho e adolescentes e as relações entre socioeducação e integralidade em saúde. $O$ universo de estudo foi constituído pelas equipes técnicas, de socioeducadores e de gestores, com atuação nas três unidades de semiliberdade do Distrito Federal. A pesquisa realizada teve uma natureza qualitativa, e o estudo de caso como método de pesquisa adotado, se configurando como um estudo de caráter descrito e exploratório, havendo pesquisa com o universo das três casas de semiliberdade do DF. As técnicas e instrumentos de coleta de dados constaram de análise documental; revisão bibliográfica; observação participante e entrevistas semiestruturadas.
\end{abstract}

\footnotetext{
${ }^{1}$ Graduado em pedagogia com habilitação em magistério das séries iniciais do ensino fundamental e gestão escolar; especialista em educação e promoção da saúde; especialista em educação para diversidade e cidadania; especialista em análise política e políticas públicas; mestre em Ciências e Tecnologias em Saúde, pela Faculdade de Ceilândia da Universidade de Brasília.
2 Professora adjunta da Faculdade de Ceilândia da Universidade de Brasília, onde foi coordenadora do Curso de Graduação em Saúde Coletiva. Membro do Grupo Gestor do Projeto de Pós-Graduação Fortalecimento do Ensino na Saúde no contexto do SUS, do Instituto de Psicologia/Faculdade de Ceilândia, da Universidade de Brasília .
${ }^{3}$ Professor adjunto da Universidade de Brasília, lotado no Departamento de Saúde Coletiva da Faculdade de Ciências da Saúde. Professor do Programa de Pós-graduação em Ciência e Tecnologia da Faculdade de Ceilândia-UnB e membro do corpo docente do Projeto de Pós-graduação Fortalecimento do Ensino na Saúde no contexto do SUS, do Instituto de Psicologia/Faculdade de Ceilândia, da Universidade de Brasília.


Palavras-chave: semiliberdade, menor infrator, pedagogo, integralidade.

\section{Abstract}

This article has as aim discuss the pedagogue contributions as a member of mutilprofessional teams that have as work ensure total attentions and care to teenagers in law conflict. This way, it hopes to characterize integrality in health at semiliberty; specify the pedagogue role working in non school places; verify inter relations between team work an tennagers and social educational relations and integrality in health. This study was made by technical teams of social educators and managers, acting in the three semiliberty units in DF. The search done has qualitative nature, and the study of case as research method used, as explanotory and descriptive. The techniques snd tools to collect datas have documental analysis; bibliographic revision, participative observation and semi structuresd interviews.

Keywords: semiliberty, minor, pedagogue, integrality.

\section{Introdução}

$\mathrm{N}$

o Brasil, os direitos dos adolescentes, bem como a estruturação de ações e políticas voltadas para a sua garantia e as discussões sobre as especificidades deste grupo social, estão sendo amparadas pelo Estatuto da Criança e Adolescente (ECA) e pela Constituição Federal (CF). Da mesma forma, ao ritmo das necessidades que emergem dessa questão, a incorporação do pedagogo na equipe de socioeducação do adolescente infrator é relativamente recente e vem demandando deste profissional atualização e ampliação das suas competências e habilidades de forma a qualificá-lo para atuar em contextos não escolares e contribuir com o processo socioeducativo desse segmento populacional em unidades de semiliberdade.

A atuação junto ao menor infrator e suas respectivas famílias exige, do profissional que trabalha no regime socioeducativo, o domínio de um conjunto de técnicas e procedimentos que devem ser pautados pela compreensão da delinquência como um fenômeno complexo cuja análise, abordagem e intervenção devem levar em conta a realidade desse grupo social, suas necessidades, interesses e especificidades.

O projeto das medidas socioeducativas no Brasil é desafiador, sendo uma ruptura de paradigmas entre o que era vivenciado pelo adolescente e o novo regime que o mesmo irá enfrentar. Segundo Costa (2001), os adolescentes em conflito com a lei necessitam tanto de ajuda pessoal quanto social para os enfrentamentos que irão encontrar nesta nova etapa 
da vida. Para Costa e Assis (2006), o regime socioeducativo que tende a levar o adolescente a uma reflexão profunda sobre seus atos e sua existência, processo que presumidamente o dará confiança e de segurança. Trata-se de um processo que exige resiliência, o deveria ser trabalhado em momentos oportunos durante o período de cumprimento e vivência da medida socioeducativa que Ihe foi aplicada.

Para o adolescente, é fundamental que Ihe seja assegurada uma abordagem integral de atenção e de cuidado, afinal a adolescência, como etapa do desenvolvimento, deveria implicar práticas educativas voltadas à formação do ser humano, nos termos propostos por Rodrigues (2000) e a criação de instrumentos de transformação sociais e absolutamente associados aos processos de ação comunitária e libertária (Bordenave, 2002), o que requer a compreensão da educação, como sendo capaz tanto de permitir a substituição de antigos e arraigados hábitos quanto de promover novas práticas participativas e transformadoras (Freire, 1996).

$O$ adolescente que se encontra em conflito com a lei ou em cumprimento de medida socioeducativa precisa ser amparado e mobilizado para seguir seu caminho e avançar tanto na garantia de seu percurso de aprendizagem quanto da promoção de sua saúde.

No caso específico desse artigo se buscou no conceito de integralidade, nos termos defendidos pelo campo e à área da saúde, a base para discussão da ação do pedagogo e de suas contribuições na implementação de práticas e ações educativas em instituições socioeducativas.

Integralidade, conforme argumenta Mattos (2004), é um dos princípios norteadores do Sistema Único de Saúde (SUS), fruto do movimento sanitário, parte da luta do povo brasileiro por uma ampla reforma social, cujas metas traziam, dentre outros desafios, a busca por melhorias na saúde coletiva. No entanto, ainda segundo este autor, dentre os princípios do SUS, o da integralidade é o menos perceptível, porque está ligado a questões que não se limitam ao campo ou à área da saúde propriamente dita, pois depende, em grade medida, de ambientes, espaços e articulações intersetoriais para a sua efetivação.

Desenvolvido a partir dos resultados de pesquisa realizada no âmbito do Programa de Pós-Graduação em Ciências e Tecnologias da Faculdade de Ceilândia, da Universidade de Brasília, na linha de investigação intitulada Saúde, Educação e Ambiente de Trabalho, com temática em Práticas de Educação Popular, o artigo visa discutir as contribuições do pedagogo como membro de equipes multiprofissionais que atuam em espaços educativos não escolares é que têm como atribuições a garantia do cuidado e da atenção integral de adolescentes em conflito com a lei. Nesse sentido, busca caracterizar a integralidade em 
saúde no projeto pedagógico do regime de semiliberdade; especificar o papel do pedagogo em cenários de atuação não escolares; verificar as interrelações entre equipe de trabalho e adolescentes e as relações entre socioeducação e integralidade em saúde. Os procedimentos metodológicos fundamentaram-se em um estudo de caso exploratório com base na análise de conteúdo, na qual foi privilegiada a linguagem, a comunicação e a fala dos participantes.

Esta pesquisa foi aprovada pelo Comitê de Ética e Pesquisa em Saúde da Universidade de Brasília em $1^{ㅇ}$ de abril de 2016. Tendo como Número do Parecer: 1.474.744.

Os participantes foram os membros das equipes multidisciplinares, independentemente de sua categoria profissional, tendo sido utilizado como critério de inclusão o caráter efetivo e o pleno exercício de suas funções há mais de um ano, independentemente da escolaridade, em Unidades de Semiliberdade do Distrito Federal. A coleta de dados constou de análise documental, revisão bibliográfica, observação participante e realização de entrevistas semiestruturadas.

\section{Desafios para a construção das relações intersubjetivas em espaços socioeducativos.}

\section{Esse adolescente, quem é?}

As características mais visíveis do adolescente são o seu desenvolvimento físico, com transformações internas e externas, mudanças no campo cognitivo, afetivo, surgimento dos desejos sexuais e isolamento familiar, dentre outras.

Para Zagury (1997), adolescência se define por ser uma etapa de desenvolvimento extremamente importante, que ocorre entre a infância e a juventude, quando acontecem mudanças corporais, emocionais e afetivas, com variações de cultura para cultura, de grupo para grupo, e até entre indivíduos de um mesmo grupo. O autor considera a adolescência como aquela fase em que esse segmento se sente dono de si próprio; na qual a preocupação com a escola fica em segundo plano e as novidades da vida vêm cheias de encantos, atrativos e prazeres.

No tocante às distinções que podem condicionar a configuração dessa fase, Backer (1994) chama a atenção para o fato de que os adolescentes de classes sociais mais privilegiadas buscam um tipo de lazer mais associado à cultura - como cinema, teatro, restaurantes, bares, boates, entre outros -, enquanto os de classes sociais menos 
favorecidas costumam buscar outras formas de lazer, como assistir televisão, ouvir música, conversar com os amigos, praticar esportes em campos comunitários, entre outros. Tais atividades não dispensam a supervisão dos pais, responsáveis e educadores, sobretudo no que se refere ao desenvolvimento de valores como bases para a vida, o que faz com que haja necessidade de cuidado, por exemplo, em relação à exposição à mídia, à internet e, principalmente, às amizades que os cercam, pois os grupos se fortalecem no âmbito de seu próprio segmento, o que representa fator e forte influência em suas escolhas e pensamentos.

No entanto, este tipo de supervisão não supõe medidas que sufoquem, prendam ou exponham o adolescente. Ao contrário, ele implica uma presença e um cuidado mais próximo e o conhecimento sobre o cotidiano desse adolescente, sendo importante conhecêlo, estar em seu convívio, ter clareza das suas limitações, seus anseios e desejos, sabendo que a adolescência é uma fase e que, como tal, não vai durar a vida toda, pela qual alguns passam com muita tranquilidade; outros com mais rebeldia ou com muita timidez, medo e angústias.

Há, portanto, nas instituições educativas, sejam elas escolares ou não escolares, cuja função social é uma atribuição compartilhada que deve orientar a condução e mediação de temáticas transversais nas práticas educativas e ou socioeducativas, uma vez que, de acordo com a Constituição Federal, não cabe exclusivamente às escolas à tarefa de educar. "É dever da família, da sociedade e do Estado assegurar à criança e ao adolescente, com absoluta prioridade, o direito à vida, à saúde, à cultura, à alimentação, à dignidade, ao respeito, à liberdade e à convivência familiar e comunitária, além de colocálos a salvo de toda a forma de negligência, discriminação, exploração, violência, crueldade e opressão". (CONSTITUIÇÃO FEDERAL, 1988. Art . 227).

As intervenções educativas e as socioeducativas ocorrem por meio de atividades lúdicas, recreativas, esportivas, ocupacionais, de preparação para o trabalho e de atenção e de cuidado à saúde. Na perspectiva da integralidade da saúde visariam, sempre, o desenvolvimento biopsicossocial dos adolescentes em regime de semiliberdade, mediado por um espaço relacional capaz de propiciar interações, troca de experiências e a descoberta de formas criativas e eficazes para a superação das condições de fragilidade em que se encontram os adolescentes, pois trabalho grupal cria e fortalece vínculos que podem desencadear efeitos positivos.

Durante a busca pela autonomia, o adolescente almeja autossuficiência, autossustento e autoafirmação. Por vezes, nessa busca, o adolescente se coloca à margem 
social, como forma de se afirmar, ser autêntico e se diferenciar dos demais. De uma forma geral, as capacidades e oportunidades de desenvolvimento próprios da adolescência não ocorrem de maneira uniforme ou linear. Elas são determinadas e influenciadas pelas condições concretas de sua existência, assim como pelos contextos históricos e culturais nos quais se inserem.

Para Sudbrack (2003), ao se trabalhar com adolescentes em contextos de vulnerabilidade social e em conflito com a lei, as questões relacionadas à exclusão e inclusão social requerem uma compreensão acerca da condição complexa sob a qual eles vivem, e na qual se concretizam e se desenvolvem as relações interpessoais que estabelecem. Sobre essa mesma questão, Wanderley (1999) argumenta que qualquer estudo sobre exclusão social deve ser contextualizado no tempo e no espaço, uma vez que "os excluídos não são apenas rejeitados física, geográfica ou materialmente, mas de todas as riquezas espirituais, seus valores não são reconhecidos, há também uma exclusão cultural" (p. 17), Ihes sendo negados direitos básicos.

Para Minayo (2001), é preciso lutar contra a naturalização destes processos sociais de exclusão que leva à desesperança com relação aos adolescentes, e resultam na sensação de que sua contribuição social seja desnecessária. Para mudar esta realidade é necessário tratar esses indivíduos como pessoas capazes de escolher, aprender, compreender, ser e de tomarem decisões. Dentro de uma realidade social específica, estes adolescentes devem produzir sentidos sobre suas vidas e as dos outros. Como argumenta Olivesnstein (1997), a definição de exclusão e de margem, a priori "parece simples: se situa em relação à norma. No entanto, não sabemos de qual norma se trata, no entanto não sabemos a relação que cada um de nós sustenta, psiquicamente, com a mãe, a família, as instituições" (p. 18), o que nos permite afirmar que os conceitos de margem, desvio e exclusão social na adolescência não podem ser definidos ou compreendidos sem que se compreenda, também, o universo relacional do adolescente, ou seja, sem que se entenda como sua rede social e pessoal foi constituída.

Para o adolescente, que vive em uma sociedade cheia de normas e critérios, é fundamental tanto a construção de vínculos e laços coletivos, quanto poder contar com de políticas públicas com foco no trabalho, na educação e na saúde.

\section{A intervenção técnica institucional e os princípios da integralidade em saúde no regime socioeducativo de semiliberdade}


O Estatuto da Criança e do Adolescente (ECA) determina a necessidade de uma proposta técnica de trabalho para a aprovação e o credenciamento de instituições de atendimento social. Como destaca Varela (1988), uma proposta de intervenção junto aos adolescentes em situação de risco deve ser educativa e buscar identificar o problema e suas implicações subjetivas. No entanto, é importante ressaltar que para entender a dinâmica do adolescente, deve-se fazer uma proposta de intervenção que seja coletiva, que envolva os atores sociais da comunidade em que o adolescente está inserido, ou seja, pais, namoradas (os), parentes e todos aqueles que exercem um papel junto ao adolescente, e considerar fatores biopsicossociais e condicionantes econômicos, culturais, comunitários, dentre outros. Tal intervenção deverá, também, ser entendida no núcleo base da vida desse adolescente - que é a família - pois a reorganização dessa célula contribui diretamente para a sua ressocialização.

Da mesma forma, é importante buscar investigar e compreender os valores, as expectativas, as fantasias e as referências que orientam os membros da equipe profissional da instituição que agora participam ou respondem direta ou indiretamente pelo processo socioeducativo desse adolescente.

Para que essa proposta de intervenção tenha êxito se faz necessário um ambiente que possibilite a reconstrução das percepções individuais e coletivas, uma nova visão de mundo e de ambiente, que crie novas modalidades de comunicação com proposta técnica de intervenção junto com esse segmento.

Suldbrack (1996), ao se referir à nova concepção de sujeito em programas de prevenção ao uso indevido de drogas, destaca a relevância de se buscar uma abordagem transdisciplinar para sua compreensão e intervenção, sinalizando para a necessidade de o foco de investigação, nesse caso, deixar de ser o sujeito e a droga, e passar a ser a relação desse sujeito com outras pessoas, consigo mesmo, com a sociedade e com as drogas, focando nas relações interpessoais e intrapessoais. A mesma recomendação se pode fazer às instituições voltadas ao atendimento de menor infrator em conflito com a lei, em regime de semiliberdade.

As práticas educativas devem ser expressas em um contrato de trabalho, de forma explícita, abrangente e responsável, pois estes profissionais são a base para a renovação da vida destes menores, uma vez que uma relação inadequada pode comprometer todos os objetivos do trabalho a ser realizado.

Os profissionais dessas instituições representam, talvez, as últimas alternativas de desviar as tensões que emocionam e internalizam o adolescente privado de liberdade, 
portanto, a relação entre o educador, o psicólogo e o pedagogo pode representar, em alguns casos, a presença adulta e madura na experiência vivida pelo menor em atendimento.

Braga (1999) traz, como perspectiva para compreensão desta dimensão relacional entre o adolescente e o educador, psicólogo ou pedagogo, a teoria do vínculo, inserida em algumas propostas técnicas denominadas Pedagogia do Encontro. A Pedagogia do Encontro propõe um enquadramento técnico para formular uma compreensão do problema do adolescente em situação de risco ou em conflito com lei. Possibilita o desenvolvimento de um plano de intervenção, mediante hipóteses diagnósticas e de estudos de caso, buscando desvendar a rede vincular do adolescente, cujo atendimento é focado no adolescente e nas pessoas de vínculo próximo a ele.

Nele, faz-se necessária a participação da família, de organizações não governamentais, da comunidade e da escola para que o adolescente cumpra suas funções educacionais, principalmente em se tratando de adolescentes encaminhados por instituições de atendimento social, pois é notório que a relação escola, família e comunidade estabelecem elo de força na luta pela formação destes adolescentes. "Neste sentido, a formação da cidadania supõe a possibilidade de criar espaços educativos nos quais os sujeitos sociais sejam capazes de questionar, de pensar, de assumir e também, é claro, de submeter à crítica os valores, as normas e os direitos morais existentes, inclusive aqueles tidos como mais democráticos e justos". (GENTILE e ALENCAR, 2003, p. 94).

A educação é um processo integralizador. Os diversos segmentos nele envolvidos precisam trabalhar em consonância e coesão, entender que a medida socioeducativa exerce papel fundamental - não apenas na reinserção social, como também na prevenção da marginalização dos adolescentes em situação vulnerável - e tem papel de extrema responsabilidade no cumprimento do seu papel educativo.

Isso significa dizer que cabe às instituições educativas não escolares, tanto quanto a escola, o dever de implementar práticas pedagógicas que despertem nesses adolescentes o desejo pela aprendizagem, fazendo uso de didáticas e metodologias que minimizem frustrações e que contribuam para o sucesso escolar, tendo em vista a existência recorrente de uma expressiva defasagem entre idade e escolaridade, de históricos de uso de entorpecentes, maus tratos, vida na rua ou privação de liberdade.

De acordo com o ECA, a escolarização do adolescente em regime de semiliberdade é obrigatória e prevista para ser realizada pelas instituições que realizam o atendimento social (Artigo no 102) já que, no Brasil, a escolaridade constitui-se direito fundamental 
(BRASIL, 1990). O fenômeno da marginalidade e da evasão escolar desse segmento populacional frequentemente está associado à repetência ou à sua expulsão do sistema de ensino.

Da mesma forma, a questão do trabalho e da profissionalização, precisa ser considerada, uma vez que encaminhar um adolescente para o mercado de trabalho não é tarefa simples, com resultados seguros e tranquilos. Há que se contextualizar a inserção do adolescente no trabalho, compreendendo os fatores que podem determinar seu sucesso ou fracasso. Conforme Dauster (1992), o trabalho assume significados múltiplos, além de seu aspecto econômico. Assume, por exemplo, valor de troca para o adolescente, traduzindo-se como retribuição, ao pai ou mãe, pelos bens e cuidados a ele proporcionados. Há necessidade de o adolescente compreender que seu ingresso nesse mercado se dará basicamente por duas vias: escolarização e profissionalização. Nesse sentido, as unidades de semiliberdade ao estruturarem seus projetos devem considerar a necessidade de trabalhar aspectos que podem implicar na qualidade das relações interpessoais, fundamentais para que obtenham sucesso em ambas as vias.

Para Erikson (1972), essas questões são internalizadas, pois, muitos dos adolescentes passam a reafirmar a identidade de delinquente ou a procurarem reforçar seu estigma de invisíveis. Desta forma, preferem pertencer a um grupo a se sentirem segregados. Uma vez preparados para assumirem responsabilidades e os compromissos inerentes ao trabalho, cabe à instituição de atendimento garantir a chance real de o adolescente vivenciar uma relação de emprego ou profissionalização formal. Trata-se de encontrar o lugar onde o adolescente vai trabalhar, ou seja, organizar as bases materiais do processo, tal como proposto por Gomes da Costa (1991).

No tocante à promoção da saúde, para Costa e Assis (2006), ela assume, em sua prática de atenção e de cuidado, uma diferenciação daquelas tidas como tradicionais, baseadas exclusivamente no modelo médico-curativo. Para estes autores, a perspectiva de promoção da saúde possui características mais acentuadas que dizem respeito à integralidade em saúde, com aspectos voltados à vida e à alimentação saudável, à garantia de habitação, transporte, educação, renda, lazer, cultura, emprego, liberdade e acesso aos serviços e políticas essenciais ao seu desenvolvimento. Os princípios da integralidade, as práticas de educação e promoção da saúde implicam um novo conceito sobre bem-estar, viver bem, qualidade de vida e vida saudável.

Ainda de acordo com estes autores, os conceitos de reparação, correção, recuperação além de desatualizados trazem consigo estigmas. Por essa razão, novos 
conceitos são necessários - como os de promoção da saúde e cuidado integral que implicam a adoção de novos comportamentos e hábitos que contribuem para qualidade de vida, com intuito de evitar agravos na saúde.

No caso de ações realizadas no âmbito das instituições, se faz necessário conhecer o Projeto Político-Pedagógico (PPP) da instituição. Para Gadotti (2001), o PPP é a compreensão da dimensão política e pedagógica das práticas institucionais, cuja interface permite a correlação entre a reflexão da ação e o que se desenvolve na prática.

Da mesma forma, a relação com a comunidade, decisões assumidas como compromisso de induzir e formular processos que produzam conhecimento e de constituir cidadãos autônomos no processo de escolha e decisões são aspectos que devem ser considerados nos PPP.

Partindo do modelo de vigilância à saúde, é possível entender que um PPP deva prever a possibilidade de formulação e implementação de políticas públicas saudáveis, e um conjunto de ações governamentais (intra e intersetoriais) e não governamentais voltadas para a melhoria das condições de vida das populações, seja qual for essa população ou comunidade para a qual se orienta (escolar, prisional, hospitalar, militar, organizacional entre outras) e a reorganização das ações, sob a responsabilidade direta do sistema e dos serviços de saúde.

Para dar conta do princípio da integralidade, dada a sua complexidade, deve-se pensar tanto em uma perspectiva de organização dos serviços, segundo níveis de complexidade tecnológica, quanto na articulação entre ações de promoção da saúde, de prevenção de riscos, de assistência e de recuperação da saúde. "O PPP deve prever uma combinação de estratégias que envolvem a ação do Estado (políticas públicas saudáveis), do sistema de saúde (reorientação do sistema de saúde) e de parceiras interinstitucionais, trabalhando com a proposta de responsabilização múltipla, seja pelos problemas, seja pelas soluções propostas para os mesmos" (BUSS, 2003, p. 15; apud TEIXEIRA, 2005).

A má condição de saúde das populações é resultante, em grande medida, da má distribuição de renda e das grandes desigualdades sociais, sanitárias, além da falta de oportunidades e de políticas de igualdade, e se torna fator determinante, gerado pelas consequentes injustiças que afetam as condições de vida da população, de forma imediata e visível (acesso à atenção à saúde, à educação, às condições de trabalho, esporte, lazer, cultura, profissionalização e à habitação) e a possibilidade de ter uma vida próspera.

Para a Comissión sobre Determinantes Sociales de la Salud (2008), corrigir essas desigualdades é uma questão de justiça social e um imperativo ético para o qual devem ser 
estruturadas três grandes linhas de ação: melhorar as condições de vida da população; lutar contra a distribuição desigual do poder e dos recursos; e medir a magnitude do problema, avaliar as intervenções, ampliar a base de conhecimentos, dotar-se de pessoal capacitado em determinantes sociais da saúde e sensibilizar a opinião pública a esse respeito.

Esta noção de determinação social da saúde está alicerçada num fundamento ético que é a equidade em saúde. As iniquidades em saúde são diferenças socialmente produzidas, sistemáticas e evitáveis. Dessa forma, a prática pedagógica contextualizada desde a perspectiva da integralidade em saúde deve estar contida no projeto pedagógico das instituições escolares, socioeducativas, centros de saúde e outras que atuam diretamente com a população. A integralidade em saúde, nos termos preconizados pelo Sistema Único de Saúde (SUS), busca estabelecer parâmetros de vida saudável aos sujeitos sociais de direito.

Embora cunhado no setor saúde, o conceito de integralidade também diz respeito a outras diferentes dimensões do cuidado e da atenção a pessoas, grupos populacionais específicos ou comunidades. Nesse sentido, conhecer as contribuições que o pedagogo, como membro de equipe multiprofissional, atuante em instituição não escolar, pode contribuir para ampliar a discussão sobre competências e responsabilidades dos envolvidos com o desenvolvimento de adolescentes em cumprimento de medida socioeducativa, de uma forma geral, e em semiliberdade, de uma maneira específica.

\section{Sobre o pedagogo, sua formação e responsabilidades}

Os cursos de formação superior em pedagogia têm uma preocupação central relacionada à formação de profissionais capazes de organizar, sinalizar, orientar, pontuar e entender situações de ensino e aprendizagens, independentemente do cenário educacional no qual o pedagogo for atuar. Mas, em sua preparação para o trabalho docente há desafios. "Estudos sociológicos sobre as profissões demonstram uma evolução clara no decorrer dos últimos anos e na maior parte dos ofícios relativos aos profissionais das ciências humanas: enfermeiros, assistentes sociais, jornalistas e professores. Assim, para responder aos desafios sem procedentes das transformações necessárias dos sistemas educacionais, o papel dos professores deve, necessariamente, evoluir". (PERRENOUD, 2001, p. 11). 
A ampliação do campo de atuação do pedagogo parte de uma nova concepção acerca do processo de trabalho como delimitador de um espaço relacional, se constituindo um princípio educativo. Nesse sentido, se pode inferir que as diferentes instituições normatizadoras da vida em sociedade são portadoras de um projeto pedagógico, o qual pode ser implícito ou explícito.

Perrenoud (2001) afirma que o professor é capaz de analisar situações complexas, tomando como referência diversas formas de leitura; optar de maneira rápida e refletida por estratégias adaptadas aos objetivos e exigências éticas; escolher, entre uma gama de conhecimentos, técnicas, instrumentos e meios mais adequados, estruturando-os na forma de um dispositivo; adaptar rapidamente seus projetos em função da experiência; analisar de maneira crítica suas ações e seus resultados; e, enfim, aprender, por meio dessa avaliação contínua ao longo de toda sua carreira. Tais considerações são importantes na construção da prática pedagógica e na evolução desse ofício em qualquer lócus educacional, seja ele constituído no campo da educação ou da saúde, por exemplo.

A prática educativa é exercida, portanto, em várias instâncias e cenários, seja ela escola, espaço comunitário, unidade de saúde, presídio, hospital, asilo, sanatório, creche, orfanato ou unidade de regime socioeducativo. Ou seja, conforme defende Bauman (1999), a profissão do professor é necessária nas instituições totais, sendo este um profissional que humaniza, emancipa e politiza, mediante sua prática educativa, como afirma Perrenoud (2001).

"Profissionalização é constituída, assim, por um processo de racionalização dos conhecimentos postos em ação e por práticas eficazes em uma determinada situação. O profissional sabe colocar suas competências em ação em qualquer situação; é o "homem da situação", capaz de "refletir em ação" e de adaptar-se, dominando qualquer situação. E um profissional admirado por sua capacidade de adaptação, sua eficácia, sua experiência, sua capacidade de resposta e de ajuste a cada resposta e de ajuste a cada demanda". (ALTET, 2001, p. 25).

Em outras palavras, o profissional da educação deve ser capaz de elaborar suas práticas pedagógicas de acordo com as necessidades enfrentadas, destacando a competência para atuar em cenários e contextos diversos e para saber lidar com a singularidade dos sujeitos com os quais interage.

Os sentidos que constituem o pedagogo como trabalhador no âmbito das unidades de semiliberdade resultarão da interação ou não interação que ele estabelecerá com os demais membros da equipe multidisciplinar composta basicamente por psicólogos, assistentes sociais e agentes socioeducadores. 
Assim, a qualificação do profissional da educação e suas competências estão voltadas para o outro, ou seja, aquele que usa a estrutura educacional (escolares, familiares e comunidade escolar), cujo modelo de práticas pedagógicas tem sido discutido amplamente no intuito de melhorar o atendimento educacional e de formar profissionais qualificados para atuarem em espaços institucionais distintos.

O processo educativo e a prática docente em diferentes cenários acrescentam complexidade ao trabalho do pedagogo, que passa a ter que responder, de forma qualificada, com a criação, ampliação e diversificação de modelos, técnicas, conhecimentos e práticas formativas, para além do que se já dispõe a partir do próprio saber pedagógico. No caso específico do trabalho em instituições voltadas para o segmento adolescente em cumprimento de medidas socioeducativas, saberes sobre a natureza do espaço institucional e organizativo em que ele atua e as diferentes expressões da complexidade do trabalho formativo, são fundamentais.

\section{DISCUSSÃO E ANÁLISE DOS DADOS}

\section{Sobre a constituição do pedagogo como protagonista no processo de socialização}

Entende-se que a constituição do pedagogo no espaço das unidades de semiliberdade se opera mediante a construção de uma didática viva, ou seja, uma prática pedagógica emancipatória e libertária necessária para a superação das condições de carência e de exclusão dos adolescentes internos. Segundo Libâneo (2006), a didática e as práticas pedagógicas estão fortemente ligadas à relação ensino-aprendizagem e envolvem o desenvolvimento de funções cognitivas, visando à aprendizagem autônoma. "Os pedagogos começam a compreender que a tarefa da escola contemporânea não consiste em dar as crianças, jovens ou adultos, uma soma de fatos conhecidos, mas em ensiná-los a orientar-se independentemente na informação científica e em qualquer outra. Isso significa que a escola deve ensinar os alunos a pensar, desenvolver ativamente neles os fundamentos do pensamento contemporâneo para o qual é necessário organizar um ensino que impulsione o desenvolvimento". (LIBÂNEO, 2006, p. 3).

No contexto de uma unidade de semiliberdade, esse ensino que desenvolve o pensamento é importante, sobretudo em função de as fragilidades cognitivas serem impares entre os internos, o que demanda uma prática pedagógica orientada pela multiprofissionalidade, interprofissionalidade e pela interdisciplinariedade, como condições para o desenvolvimento integral dos adolescentes. 
A prática desenvolvimental, para Libâneo (2006), traz implicações importantes para o ensino, pois se está mudando a forma como se aprende, devendo haver, por parte dos profissionais da área da educação, igual mudança na forma como se ensina e transformações acerca da percepção que têm com relação à aprendizagem do educando. Os profissionais da educação devem se envolver como sujeitos participantes do processo de constituição do indivíduo, uma vez que a prática pedagógica em unidades de semiliberdade deve levar em conta um pensar e fazer diferentes, o que requer busca por didáticas mais adequadas.

Segundo Luckesi (1994), a didática é um direcionamento imediato das configurações do ensino e da aprendizagem, o que impõe aos pedagogos e demais socioeducadores, a habilidade de transformarem teorias pedagógicas em práticas pedagógicas de ensino e aprendizagem, o que incide diretamente sobre a construção da identidade docente, como afirma Libâneo (2006), já que como profissão a docência vem responder às necessidades sociais, pois, a prática pedagógica e o trabalho docente devem ser vistos e elaborados como fontes de transformação das realidades sociais. Para estes autores, os professores passam, no decorrer de sua formação continuada e prática profissional, construindo e reconstruindo significados e sentidos sobre sua própria prática pedagógica.

Eles não apenas produzem transformações sociais como, de acordo com MarinhoAraújo e Almeida (2008), atuam em contextos de redefinição e transformações constantes, que oscilam entre o avanço e a cristalização tanto de conhecimentos quanto de fazeres pedagógicos que deveriam estar, como sinaliza Guzzo (2003), efetivamente orientados para a libertação.

Nos termos que propõe Luckesi (1994), seria necessário que os pedagogos e educadores sociais compreendessem a a intencionalidade da socioeducação como uma prática social, que confere direcionamento para a vida futura dos adolescentes, que se revela na sua dimensão política e como tal deve ser apropriada pelos adolescentes. Por outro lado, aos socioeducadores estaria colocada a necessidade de, ao lidarem com menores infratores, vivenciarem essa prática social, associada e integralizada, como sendo pedagógica.

Os profissionais que atuam em unidades de semiliberdade dispõem de um espaço de ensino-aprendizagem que, por vezes, se constitui extensão do ambiente escolar, familiar e social, uma vez que a função dessas unidades, descrita pelo Estatuto da Criança e do 
Adolescente (ECA) e direcionada pelo Sistema Nacional de Atendimento Socioeducativo (SINASE), é de socioeducar.

Nesse esforço, ao papel do pedagogo se acrescentam atributos relacionados à capacidade de mediar processos e de favorecer a lida, por parte dos adolescentes, com um mundo em transformação, cujos valores humanos e éticos precisam ser reafirmados cotidianamente, precisam criar oportunidades para que sejam feitas reflexões profundas, incluindo aquelas sobre eles mesmos.

O pedagogo, com base em suas habilidades e competências, deve agregar valores em suas práticas, como condição primordial para assegurar os percursos formativos dos adolescentes em cumprimento de medidas socioeducativas, e favorecer o estabelecimento de um ambiente onde o menor infrator tenha condições reais de se desenvolver. $O$ educador que atua na perspectiva humanizada de cuidado e atenção possui maiores chances de conseguir estabelecer um vínculo com os educandos, visando à construção de uma sociedade mais igualitária, politizada, escolarizada e justa.

Investigando as relações que permeiam o trabalho pedagógico e a função do pedagogo em uma unidade de semiliberdade, engendram-se diversos olhares e percepções com ausência e presença da sua atuação no que se refere à integralidade em saúde. A atuação desse profissional ocorre em contexto de diversidade de pensamentos e práticas, sendo o local de sua atuação tido como estigmatizado, marginalizado e complexo. Conforme Dauster (1992), o trabalho pedagógico, em geral, assume significados múltiplos, além da complexibilidade de seu aspecto. O processo de socioeducação deveria ser mais amplo, com ajuda da rede de serviços públicos em específico. A construção de programas específicos para esses adolescentes seria primordial para a melhoria do processo e do que é proposto pelo ECA.

"O pedagogo no sistema é muito recente, antigamente era só psicólogo e assistente social, agora que o pedagogo está sendo mais bem aceito, por que antes o pensamento era que a função do pedagogo era só escola e a percepção era que não tinha necessidade desse profissional na equipe técnica, até quando eu entrei ainda passei por situações de pessoas que tinham esse pensamento. Se o próprio SINASE, determina que a equipe técnica é composta por um psicólogo, assistente social e pedagogo não é à toa a necessidade desse profissional nesse lócus de atuação. O lugar do pedagogo é um lugar de vivências educativas, sociais e cognitivas. Mas aqui eu não faço o trabalho de pedagogo, isso é em todo sistema, eu faço um trabalho técnico, ou seja, existe um trabalho pedagógico, psicológico e ou social, existe em todo sistema do DF um trabalho técnico, o menino que eu tomo conta eu faço às vezes dos três técnicos. Hoje no sistema não existe um trabalho especialista, existe um trabalho generalista". (Participante Profissional de Socioeducação Psicólogo 3). 
O processo socioeducativo, nos termos encontrados no ECA e no SINASE, precisa estar expresso no trabalho pedagógico realizado nas unidades de semiliberdade. Para tanto, o papel do pedagogo deve ser do profissional que se constitui elo entre os profissionais que atuam na unidade, uma vez que a essência de sua atuação é formativa. Ele é, no pensamento dos demais técnicos e socioeducadores, o idealizador do Projeto Político Pedagógico (PPP) e o organizador dos eventos das unidades, aquele que dá vida ao processo socioeducativo, o que traz novidades, aquele que motiva e ajuda os adolescentes a caminharem.

O processo de ressocialização, visão que requer um olhar para além dos muros das unidades, leva à crença de que no sistema é fundamental, para a atuação do pedagogo, a colaboração dos outros profissionais existentes na comunidade onde a unidade está inserida. "Existem duas situações: o processo de socioeducação dentro da unidade, onde a equipe desenvolve um trabalho em conjunto, não só equipe técnica, também os socioeducadores. A outra seria, não somente o trabalho dessa equipe, mas, o trabalho de outros profissionais da cidade". (Participante Profissional de Socioeducação Pedagogo 1).

É preciso compreender o processo formativo em desenvolvimento nas unidades. Para tanto, se faz necessário entender o modo como sustenta a prática pedagógica socializadora na unidade, já que a presença ou a ausência de projetos educativos que fortaleçam o trabalho e que possam levar os diferentes profissionais atuantes nas unidades (técnicos, agentes socioeducativos e gestores) a desenvolverem práticas colaborativas e interprofissionais condizentes com as diretrizes, são fundamentais.

No tocante às práticas educativas, cabe ao pedagogo analisar situações complexas, tomando como referência diversas formas de leitura do universo presente; escolher, de maneira coerente, rápida e consciente, os objetivos de ensino-aprendizagem dentro das exigências éticas da medida socioeducativa; instrumentalizar e institucionalizar adequadamente o processo de integralização do sistema socioeducativo na unidade; utilizar a experiência profissional e pessoal como recurso didático; avaliar de forma crítica a atuação das ações e os resultados; aprender a estruturar o trabalho multidisciplinar e multiprofissional de forma coerente.

"São as condições que as políticas do SINASE apontam. Vivenciar o projeto pedagógico, ter noção do que é socioeducação para além da prática, ter condição do que é o sistema socioeducativo. Nós não temos bem estruturado o projeto pedagógico e aí entram os vários olhares sobre o sistema. Já vi gente fazendo projeto para os adolescentes cantarem o hino nacional e verbalizando que isso educa, esquecendo-se do senso de cidadania, civilidade entre outros que fazem uma reeducação de verdade" (Participante Profissional de Socioeducação Pedagogo 3). 
A exigência da autoavaliação e avaliação da equipe acerca dos próprios adolescentes são importantes para o crescimento e aperfeiçoamento do próprio trabalho pedagógico. Na relação de reintegração social ou socioeducação no cenário com menores infratores, devem existir processos no qual o adolescente se sinta inserido e participante.

A estruturação do Projeto Político-Pedagógico (PPP) é fundamental para se evitar práticas sem produção de sentidos para a vida do adolescente e práticas empíricas fundamentadas em pensamentos pessoais, juízo de valores, entre outros, que coabitam na identidade profissional de muitos que exercem trabalhos em instituições totais. Para Gadotti (2001), o PPP é um instrumento que pode se constituir mecanismo de garantia de direitos, servindo como norteador das práticas e dos processos que integralizam os adolescentes aos acessos a eles garantidos por lei.

"Primeiro ter um espaço adequado, ter condições de trabalho, ter o carro, ter condições de instalações de acomodação para o menino. Você veja o menino que deita no chão por que não tem a cama onde dormir e o Estatuto garante isso. O menino dormir no chão no colchonete, isso é garantia de direito? É dignidade? Não é, não é. Você pode ver que vários artigos do ECA estão negados. Se o menino deita no chão ele está sendo tratado indignamente" (Participante Profissional Assistente Social 2).

Tais considerações são importantes na construção da prática pedagógica e na evolução desse ofício, seja ele executado em qualquer situação educacional e sob orientação de um modelo ou concepção de educação, uma vez que o exercício docente é feito em várias instâncias e cenários.

É possível afirmar que o educador é autônomo, com habilidades e competências específicas, marcadamente adquiridas ao longo de sua prática pedagógica, cuja atuação se prevê tanto em espaços educacionais formais quanto não formais. O espaço de semiliberdade, nesse sentido, é educativo por natureza já que, por definição, responde pelo acesso à educação, à profissionalização, à saúde, à cultura, ao esporte, ao lazer e à espiritualidade de adolescentes cumprindo medidas socioeducativas. No entanto, essa função social e educativa delegada às unidades de semiliberdade pode ser negligenciada ou desconhecida por alguns profissionais, por razões que podem estar relacionadas à excessiva burocratização existente nesses espaços, que findam por impedir ou comprometer o estabelecimento de vínculos efetivos do processo de socioeducação, como instituído legalmente.

"Tem muita atividade para o pedagogo, é necessário de mais, o acompanhamento pedagógico com a avaliação. Temos menino no $5^{\circ}$ ano que não sabe escrever o nome. Garantir um reforço escolar, garantir alguma coisa para esse menino, lutar pra que a própria escola dê um suporte e 
acredite no processo socioeducativo. Tem uma socioeducadora que começou nesse semestre um trabalho de reforço escolar, está sendo um sucesso, mas isso foi de iniciativa própria. Difícil ter possibilidades em um trabalho onde fazem relatórios abreviados para o menino sair da medida e a casa ficar vazia, verbalizam que o adolescente é um santo para o juiz o liberar da medida por que ele dá mil trabalhos. A casa feminina daqui do Gama foi fechada porque, quando a Secretária chegou lá pegou as adolescentes fumando maconha, no outro dia no diário oficial saiu à ordem de fechamento da unidade em 30 dias. Aqui são meninos de 16, 17 e 18 anos, mas aqui a referência é 17 anos. Essa fase, eu acredito que seja a mais difícil do adolescente. Por esse motivo, todas as possibilidades de ressocialização deveriam ser acrescentadas na unidade". (Participante Profissional de Socioeducação Psicólogo 2).

A burocratização do serviço e o excesso de relatórios e de documentos impedem uma prática pedagógica mais eficaz. O papel do socioeducador é de um facilitador das práticas educativas, sendo necessários projetos que deem voz ao socioeducador e visibilidade às práticas que sejam efetivadas por esse profissional.

"Esse projeto pedagógico existe, mas não foi executado por nós, faz parte de nosso acervo, das normas e direções, eu não tenho acesso a esse projeto. Como diz, projeto pedagógico está mais ligado à área da educação. Eu como assistente social, desconheço, e pelo pouco tempo mesmo que estou aqui. Nós estamos em um apaga fogo, somos bombeiros. Estamos aqui para remediar conflitos, amenizar os sintomas e não na prevenção propriamente dita. Então, esse projeto existe, e eu, particularmente, chegando há pouco tempo, executando um trabalho de especialista, não conheço" (Participante Profissional de Socioeducação Pedagogo 2).

"Eu vejo que os pedagogos, talvez sejam algo ligado à profissão, eles gostam muito de voltar o trabalho para a escola, sabendo que a pedagogia é uma área ampla, acredito que outras práticas poderiam passar pela prática pedagógica. Mesmo quem idealizou o SINASE, foi um pedagogo, Antônio Carlos Gomes da Costa. Ele deveria criar práticas, projetos e estar vivenciado mais o seu papel na medida. Outro fator é a aceitação ou não do profissional pela equipe e a judicialização do trabalho, onde ficamos, horas e horas escrevendo relatórios para o Juiz". (Participante Profissional de Socioeducação Psicólogo 3).

Tanto gestores quanto técnicos e socioeducadores desconhecem o projeto pedagógico institucional e os resultados do estudo realizado apontam para o fato de a formação, neste contexto, requerer fiscalização e gestão efetivas da medida, que faz parte de um processo avaliativo da própria eficácia do Sistema Socioeducativo.

"Eu acho que o pedagogo, ajudaria na questão de desenvolver projetos, trabalhar com atividades especificas, junto com toda equipe, ai não só o pedagogo desenvolver. Vamos fazer juntas, ele seria o responsável por traçar essa grade de atividades, por exemplo: vamos construir um grupo, vamos fazer uma atividade $x$ ou y para o jovem. Eu acho que é por aí, não sei se estou certa, mas eu iria por ai". (Participante Profissional de Socioeducação Agente Socioeducativo 1). 
Como já discutido, o PPP é uma construção coletiva, com diversos saberes e olhares, cuja efetivação e institucionalização são de responsabilidade de todos. Trazer o PPP para o dia a dia da unidade, enriquecê-lo com o que existe na comunidade local, construir subprojetos locais com a identidade da unidade, é estratégico e necessário.

"Não existiu construção coletiva, quando eu entrei já possuía um pronto para todas as unidades do DF. De acordo com o PPP, temos que trabalhar com o sistema mais próximo, falando em integralidade, teríamos que trabalhar com os sistemas mais próximos: educação, esporte, saúde e todas as políticas juntas. E temos dificuldades com isso. Ate por que a semi é diferente da internação, pois, na internação temos tudo isso lá dentro, saúde, educação, esporte. Na semiliberdade é fora, a saúde, a escola, o esporte. Tudo isso e usado os recursos da comunidade. $E$ a questão da intersetorialidade, deveríamos trabalhar em trios, pois, temos na equipe técnica. Pedagogos, assistentes sociais e psicólogos. Fora isso tem o agente socioeducador, que deveria integrando essa equipe. Como trabalhamos com superlotação não conseguimos trabalhar em equipe, dessa forma, dividimos os casos, psicólogos tantos, assistentes sociais outros, e pedagogos outros. Ainda temos dificuldades de trabalhar dessa maneira específica". (Participante Profissional de Socioeducação Assistente Social 2).

A ausência das práticas pedagógicas estabelecidas pela equipe técnica interfere no processo de integração social e na integralidade da atenção e do cuidado prestado ao adolescente, assim como na constituição de sua subjetividade, razões pelas quais cabe uma reflexão sobre o papel da equipe técnica, suas ações, no que se refere ao entendimento de medida socioeducativa que visa um olhar bem articulado, buscando respostas em outras práticas educativas e sociais. "Eu vejo que os meninos estão gostando da socioeducadora tal quando a socioeducadora tal, vai ensinar o deve de casa, matemática, escrever o próprio nome, vai fazer a pesquisa com eles utilizando livros, revistas, internet, eles ficam gostando. E o relacionamento dos meninos com a socioeducadora fica estreito, estreitam os laços afetivos". (Participante Profissional de Socioeducação Pedagogo 2).

Toda constituição identitária requer autonomia de pensamento e participação em processos de construção dos conhecimentos. Se, por um lado, o trabalho e as práticas muldisciplinares, multi e interprofissionais asseguram a integralidade no cuidado e na atenção ao adolescente em regime socioeducativo; por outro, a constituição de juízo de valores tende a contribuir para o estabelecimento de pré-julgamentos, e a cristalizar conceitos herdados de moralidade religiosa que, na maior parte das vezes, segregam, afastam e comprometem a integração do sujeito, pois, o regime de semiliberdade propõe um momento de autorreflexão das práticas delinquentes nesse período da vida. "Os 
adolescentes não entendem esse olhar por que ele não existe, eles entendem que tem que ir para escola porque a medida exige. Na relação de vigilância e punição, eles fingem que estudam para serem liberados e os técnicos fingem que ele é estudioso para não gerar conflito". (Participante Profissional de Socioeducação Pedagogo 3). "Identificar o potencial que o menino tem, para que a vida de estudo e profissional desse adolescente seja mais atrativa que o processo de delinquência. Identificar as potencialidades, dar outras atribuições para o adolescente, mostrar outros mundos e outras vivências para esse menino". (Participante Profissional de Socioeducação Gestor 2).

Um trabalho em parceria entre técnicos, gestores, socioeducadores, família, escola e comunidade seria uma forma de ação pedagógica na construção da identidade dos profissionais e na articulação da sociedade com a proposta de ressocialização e de educação de adolescentes em situação de semiliberdade.

Freire (2011), ao se referir às práticas pedagógicas, seja ela em qual cenário educativo for, aponta qualidades que o educador deva possuir. Para ele, humildade, amorosidade, coragem e tolerância são qualidades que ajudarão o educando a se relacionar com o educador e a estabelecer mais proximidade com seu próprio processo de ensino-aprendizagem.

A prática pedagógica agregada à perspectiva da integralidade em saúde tende a assegurar ética, competência e justiça social no processo de socialização de menores infratores. Essas vertentes colaboram para produzir sentido nas correlações no tocante educativo e das práticas de ensino e aprendizagem de reeducação e socialização desses indivíduos em liberdade restrita.

\section{CONSIDERAÇÕES FINAIS}

Constituída historicamente, a iniquidade social é uma característica de uma sociedade desigual, no que se refere à renda, patrimônio, cultura, educação, saúde, lazer e garantia de direitos, se constituindo uma das principais razões para a negação de bens materiais e imateriais aos sujeitos. Essa relação faz com que grande parte da população não alcance patamar mínimo de existência com dignidade, sendo esta uma característica predominante entre os adolescentes infratores.

Politicamente, cabe ao sistema socioeducativo de semiliberdade promover, defender e garantir os direitos fundamentais do adolescente que ali se encontra, evidenciando a integralização das relações sociais e comunitárias, oportunizando aos 
adolescentes uma convivência saudável e uma reflexão sobre suas ações. Para tanto, as unidades de semiliberdade devem dispor de um projeto político-pedagógico institucional que norteie as práticas, os encaminhamentos e as vivências que ocorrem em seu interior e, ao mesmo tempo, possa orientar os processo de trabalho e melhor caracterizar o papel de cada profissional que compõe as equipes que nelas atuam.

Há evidências de que a prática pedagógica no contexto dessas unidades permanece direcionada predominantemente para a escolarização formal em detrimento daquelas que buscam integrar o processo de socioeducação dos adolescentes aos demais recursos de uso coletivo, de caráter público ou privado, disponíveis na comunidade e nas famílias. Assim como foi possível observar, haver pouca apropriação do Projeto PolíticoPedagógico (PPP) no âmbito das unidades, e para além delas, assim como a ausência de um programa de educação permanente para as equipes.

As entrevistas apontaram pouca clareza com relação às identidades profissionais dos membros das equipes, a presença de relação de poder entre os mesmos, o que evidencia falta de diálogo entre técnicos e agentes. Os agentes socioeducativos afirmam não entenderem a prática profissional do pedagogo, predominando o pensamento de 0 trabalho pedagógico estar centrado na realização de matrícula dos adolescentes nas escolas e o acompanhamento das suas tarefas escolares, sendo que o papel profissional do pedagogo vai além das questões exclusivamente escolares, sendo o mesmo preparado para realizar procedimentos e técnicas que estão relacionadas a dificuldades de aprendizagem; relações interpessoais; dinâmicas em grupo e outras práticas que podem ser realizadas em espaços de educação não escolar, devendo ele atuar, também, como mediador de conflitos e formador da equipe de trabalho.

Ao pedagogo em espaços não escolares se abrem diferentes possibilidades de trabalho cujas contribuições precisam ser mais bem apropriadas, dentre as quais convém destacar:

- Ajudar os demais profissionais a conhecerem e a refletirem sobre as potencialidades e as trajetórias de aprendizagem percorridas pelos adolescentes, de tal maneira que se possam desenhar melhores estratégias que permitam ao adolescente resgatar ou estabelecer novos percursos de aprendizagem, com que tragam maior sucesso à sua escolarização e seu desenvolvimento; Participar da elaboração de propostas de educação permanente da equipe, mediante proposição de desenhos instrucionais, treinamentos, cursos de 
atualização e de aperfeiçoamento sobre temáticas relacionadas à socioeducação e ao perfil do adolescente;

- Acompanhar a implementação dos Planos Individuais de Atendimento;

- Participar diretamente de planos ou sessões psicopedagógicas;

- Contribuir na constituição da identidade profissional dos membros da equipe, sobretudo no tocante ao papel educativo de cada uma delas, e na qualificação das relações interpessoais implicadas no processo de trabalho;

- Colaborar, com o psicólogo e o assistente social, para melhor compreensão da dinâmica familiar vivida, bem como na escolha das formas de abordagem das famílias de seu envolvimento no processo educativo do adolescente, no período em que se encontra na unidade;

- Assumir papel mediador na coordenação do cuidado desses adolescentes, se colocando como elemento central no estabelecimento de fluxos, ritmos e regularidade de práticas e procedimentos de prevenção de doenças e de promoção da saúde;

- Conhecer o funcionamento das unidades de semiliberdade e se colocar como profissional capaz de agregar conhecimentos que podem qualificar o cotidiano do trabalho de socioeducadores, participando da caracterização dessas unidades como espaço social e educativo, mas que não se confundem com as de natureza escolar.

A equipe de trabalho, em sua totalidade, deve possuir um entendimento internalizado da importância do processo de socialização dos adolescentes infratores. Cada profissional das unidades é responsável por práticas formativas que devem estar sintonizadas com os parâmetros institucionais estabelecidos para cada medida socioeducativa, cujos propósitos precisam dialogar com a atenção e o cuidado preconizados pelos serviços de saúde, educação, cultura e assistência social, e com as perspectivas de profissionalização e as expectativas com relação às demandas do mercado de trabalho.

Nas unidades pesquisadas, ficou evidenciada a ausência da agenda de saúde do adolescente no PPP, o que é extremamente necessário ao diálogo com a rede de atenção à saúde existente nos territórios nos quais as unidades estão inseridas, o que poderia agilizar o agendamento de consultas, a garantia da imunização, a realização de exames, a visita de agentes comunitários em saúde, o desenvolvimento de ações educativas voltadas 
à promoção da saúde e à prevenção de agravos desses adolescentes durante sua permanência nessas unidades. O agente comunitário em saúde, como facilitador das relações entre o serviço da rede de saúde e a unidade da semiliberdade, é um profissional cuja natureza intersetorial de seu trabalho é marcadamente vinculada à promoção da saúde e deveria ser mais bem explorada nesses cenários de atenção e de cuidado.

O pedagogo, de acordo com o estudo realizado, fica envolto aos inúmeros relatórios e mergulhado na burocratização do serviço, com dificuldades para compreender e internalizar a importância que tem no sistema socioeducativo.

Nas unidades pesquisadas predominam um pensamento pessimista com relação ao futuro do adolescente, não sendo reconhecido seu potencial, com evidências de préconceitos, fortemente ancorados nas relações de poder, na conjectura de vigilância e punição constante, o que distancia o pedagogo do seu efetivo trabalho socioeducativo.

Ficaram evidentes, a partir dos resultados alcançados, tanto as contradições e os dilemas vividos pelos profissionais que atuam em unidades de semiliberdade para concretizarem a atenção e o cuidado preconizados nos marcos teórico e legal, quanto as potencialidades e as dificuldades colocadas para o pedagogo atuar nesses espaços educativos institucionais não escolares.

\section{REFERÊNCIAS}

ALTET, M. Análise das práticas dos professores e das situações pedagógicas, Porto: Porto Editora, 2001.

BRASIL. Estatuto da Criança e do Adolescente (Lei no 8069/90). Brasília, DF, 1990.

BRASIL. Presidência da República/Secretaria Nacional dos Direitos Humanos, Sistema Nacional de Atendimento Socioeducativo - SINASE, Brasília - DF, Conanda, 2006.

BRASIL. Constituição da República Federativa do Brasil. Brasília, DF, 1988.

BRAGA. G. Pedagogia do Encontro: Proposta de Intervenção da Educação Social de Rua. In: Prevenindo a drogadição entre crianças e adolescentes em situação de rua. (Orgs) CARVALHO, D.B.B; SILVA, M. T. - Brasília, MS/COSAM; UNB/PRODEC; UNDCP, (1999). BAUMAN, Z. Vida para o consumo: a transformação das pessoas em mercadoria. Rio de Janeiro: Jorge Zahar, 1999.

BECKER, D. O Que é Adolescência. Ed. Brasiliense, SP, 1994.

BUSS, P. M. Promoção da saúde e qualidade de vida. Ciência \& Saúde Coletiva. Rio de Janeiro, v.5, n.1, 2000. Disponível em: < http://www.scielo.br> Acesso em: 22 Junho. 2015. 
COSTA, A.C.G. Presença Educativa. São Paulo: salesianas, 2001.

COSTA, C.R.B.S.F.; ASSIS, C.G. Fatores protetivos a adolescentes em conflito com a lei no contexto socioeducativo. Psicologia e Sociedade, vol. 18, n.3, Porto Alegre, set/des, 2006.

DAUSTER, T. Uma Infância de Curta Duração: Trabalho e Escola. Caderno Pesquisa São Paulo no 82. São Paulo, agosto. 1992.

ERICSON, E. Identidade, Juventude e Crise. Rio de Janeiro, Zahar, 1972.

FREIRE, P. Pedagogia do Oprimido. São Paulo: Paz e Terra, 2011. Pedagogia da autonomia: saberes necessários à prática educativa. 21. ed., São Paulo: Paz e Terra, 1996.

GADOTTI, M. Projeto Político Pedagógico da Escola: fundamentos para sua realização. In: GADOTTI, M; ROMÃO, J. E. (orgs). Autonomia da Escola: princípios e propostas. 4ㄹ. Ed. São Paulo: Cortez, 2001.

GENTILI, P; ALENCAR, C. Educar na esperança em tempos de desencanto. 4ª edição. Petrópolis - RJ: Vozes, 2003.

GOMES DA COSTA, A, C. Por uma Pedagogia da Presença. CBIA, Ministério da Ação Social, 1991.

GUZZO, R.S.L. (2003). Educação para a liberdade, psicologia da libertação e psicologia escolar: uma práxis para a liberdade, in: ALMEIDA, S.F. (Org) Psicologia escolar: ética e competências para a formação e atuação profissional. Capinas/SP, Ed. Alínea, p. 169-178. Organização Mundial da Saúde - OMS. Comissión sobre Determinantes Sociales de la Salud. Subsanar las desigualdades en uma generación. Comisión. Resumem analítico del informe final: Genebra (2008),

OLIVENSTEIN, C. (1997). Toxicomania, Exclusão e Marginalidade. Em. M. Batista \& C. Inem (Orgs), Toxicomanias, Uma Abordagem Multidisciplinar. Rio de Janeiro: Satte Letras. LIBÂNEO, J. C. Que Destino os educadores darão à Pedagogia? In: PIMENTA, S.G. (Coord.). Pedagogia, Ciência da Educação? 5.ed. São Paulo: Cortez, 2006.

LUCKESI, C. Avaliação da aprendizagem escolar. Estudos e Proposições. 17. ed, São Paulo: Cortez. 1994.

MATTOS, R. A. A integralidade na prática (ou sobre a prática da integralidade) Cad. Saúde Pública, Rio de Janeiro, 20(5):1411-1416, set-out, 2004

MARINHO-ARAÚJO, C. M; ALMEIDA, S.F. (2008) Psicologia escolar: construção e consolidação da identidade profissional. Campinas, E. Alínea. 
MINUCHIN, S. Famílias - Funcionamento e Tratamento. Porto Alegre, Artes Médicas, 1982. MINAYO, M C.S. (2001) Prefácio. Em O. C. Neto, M. R. Moreira \& L. F. M. Sucena (Orgs), Nem Soldados Nem Inocentes: Juventude e Trafico de Drogas no Rio de Janeiro. Rio de Janeiro, Fiocruz.

PERRENOUD, P. Dez novas competências para ensinar: convite à viagem. Porto Alegre: ArtMed, 2001.

SADER, E. Quando novos personagens entraram em cena: experiências, falas e lutas dos trabalhadores da Grande São Paulo, 1970-80. Rio de Janeiro: Paz e Terra, 4aㅡ edição 2001. SUDBRACK, M.F.O. (2003). A Escola em Rede In: Curso de Formação em Prevenção ao Uso de Drogas para Educadores de Escola Pública. - Vol II, SENAD/MEC.

SUDBRACK, M.F.O. (1996). Construindo Redes Sociais: Metodologia de Prevenção a Drogatição e à Marginalização de Adolescente de Família de Baixa Renda. Em R.M Macedo (Org) Família e Comunidade - Coletâneas da ANPPEP. São Paulo: Associação de Pesquisa e de Pesquisadores em Psicologia.

ZAGURY, T. Sem Padecer no Paraíso, em Defesa dos Pais ou Sobre a Tirania dos Filhos, RJ, Record, 1991.

ZAGURY, T. Adolescente por Ele Mesmo. Rio de Janeiro, Record, 1997.

VARELA, F. El Círculo Creativo, Esbozo Histórico Natural de La Reflexividad. In: WATYSLAWICK, P. Realidade Inventada. Buenos Aires, Gedisa, 1988.

WANDERLEY, M B. (1999). Refletindo Sobre a Noção da Exclusão. Em B. Saraiva (Org), As Artimanhas da Exclusão: Análise Psicossocial e Ética da Desigualdade Social. Rio de Janeiro, Vozes. 